\title{
Maxillary Conine Impactions in Orthodontic Patients: A Study
}

\author{
Dr Chandan Upadhyaya,' Dr Dasharath Kafle² \\ 'Associate Professor, Dept of Oral \& Maxillofacial Surgery, \\ ${ }^{2}$ Assistant Professor, Dept of Orthodontics, \\ Kathmandu University School of Medical Sciences, Dhulikhel, Nepal \\ Correspondence: Dr Chandan Upadhyaya; Email: updch@yahoo.com
}

\section{ABSTRACT}

Introduction: Dental anomalies involving alterations in number, size and structure of teeth often present a major challenge for dental practitioners. Many of these undiagnosed and untreated dental anomalies may ultimately present complex clinical problems in the areas of orthodontics, prosthodontics, endodontics and restorative dentistry. Maxillary canines are important aesthetically and functionally, but impacted ones are more difficult and time consuming to treat. Permanent maxillary canine impaction has been reported in $1-5 \%$ of the population.

Objective: To determine the prevalence of impacted maxillary canine in patients visiting to Dhulikhel Hospital, Kathmandu University School of Medical Sciences, Nepal.

Materials \& Method: The study was conducted with a total number of 341 orthodontic patients. The study consisted of clinical and radiographic examinations of the patients who visited Department for Orthodontics for orthodontic treatment. Descriptive statistics was calculated for gender groups and anatomical positions of the impacted canine.

Result: A total of 18 (5.29\%) orthodontic patients (male 5.83\%, female 5.0\%) were found to have maxillary canine impaction.

Conclusion: The prevalence of impacted maxillary canines in Nepalese orthodontic patients is $5.29 \%$. The occurrence is slightly higher in males.

Key words: canine, impaction, prevalence

\section{INTRODUCTION}

Tooth impaction can be defined as the intraosseous position of the tooth after the expected time of eruption, whereas the anomalous infraosseous position of the canine before the expected time of eruption can be defined as a displacement. Most of the time, palatal displacement of the maxillary canine results in impaction. ${ }^{1}$ However it is possible to prevent possible maxillary canine impaction by recognizing the tooth displacements early.

Maxillary canines are important aesthetically and functionally, but impacted canines are more difficult and time consuming to treat.' The eruption of permanent maxillary canine represents a complex series of events, mostly genetically based, whereby eruptive movements of the tooth germ taking place at a predetermined time and route enable the maxillary canine to find its antagonist at a predetermined occlusal plane. ${ }^{2}$
After third molar, the most frequently impacted tooth is maxillary canine. Ericson and Kurol reported the incidence of $1.7 \%$. Impactions are twice as common in females (1.17\%) compared to males $(0.51 \%)$. Of all the patients with maxillary impacted canines, it is estimated that $8 \%$ have bilateral impactions. The prevalence of mandibular canine impaction is $0.35 \%$; t the prevalence of impacted maxillary canine ranges from a minimum of $0.92 \%$ to a maximum of $4.3 \% .^{3}$

\section{MATERIALS AND METHOD}

The cross sectional observational study was conducted on orthodontic patients at Dhulikhel Hospital attended during February 2013 to July 2014. The study consisted of the examinations of 341 patients who visited Department of Orthodontics for orthodontic treatment. Patients of 15 years and above of both genders without any systemic disease, trauma or fracture of the jaw that might have affected normal growth of the dentition were included in the study. 
The patients were examined clinically and radiographically for the evidence of impacted maxillary canines with visual inspection and palpation. Clinical examination was done by conventional methods which included whole arch inspection, palpation to identify any retained deciduous canine, visualization of the canine bulge, splaying of the lateral incisors, lost space, crowding, fibrous tissue overlying the canine region, and mobility of the primary canines. A review on patient's chronological age and history of dental eruption/exfoliation pattern was taken carefully.

Clinical examination was supplemented with the radiographic evaluation to attain accurate diagnosis. Panoramic and Anterior Occlusal Radiographs were used to determine the position of the impacted canine by parallaxing technique. All radiographs were viewed on view screen with the area surrounding of the radiographs shielded with dark paper to block interfering lateral light and to improve viewing contrast. The anatomical position of the impacted canine was classified as: buccal, palatal and bucco-palatal positions.

\section{RESULT}

Among the total 341 orthodontic patients; 121 (35.5\%) were male and 220 (64.5\%) were female samples; with the mean age of 20.5 years. According to the present study; a total of $18(5.27 \%)$ patients were found to have maxillary canine impaction with male samples having 7 (5.83\%) and female samples having 11 (5.00\%) maxillary canine impactions (Table 1).

Table1: Distribution of maxillary canine impaction

\begin{tabular}{|l|c|c|}
\hline Sample & Canine impactions & Percentage \\
\hline Male $(\mathrm{N}=121)$ & 7 & $5.83 \%$ \\
\hline Female $(\mathrm{N}=220)$ & 11 & $5.00 \%$ \\
\hline Total $(\mathrm{N}=341)$ & 18 & $5.29 \%$ \\
\hline
\end{tabular}

Table 2: Pattern of maxillary canine impactions

\begin{tabular}{|l|c|c|c|}
\hline Sample & Buccal & Palatal & Bucco-palatal \\
\hline Male $(\mathrm{N}=7)$ & $4(57.14 \%)$ & $2(28.57 .1 \%)$ & $1(14.28 \%)$ \\
\hline Female $(\mathrm{N}=11)$ & $6(54.54 \%)$ & $3(27.27 \%)$ & $2(18.18 \%)$ \\
\hline Total $(\mathrm{N}=18)$ & $10(55.55 \%)$ & $5(27.77 \%)$ & $3(16.66 \%)$ \\
\hline
\end{tabular}

\section{DISCUSSION}

Information on dental anomalies in patients is fundamental for treatment planning. Various prevalence rates were reported among different ethnic groups. Ethnic background may vary the prevalence rates of some anomalies. Traits that may occur more commonly in certain ethnic groups may be considered specific to that population. ${ }^{4}$ According to Stecker et al; dental practitioners who are aware of ethnic differences in the occurrence of dental anomalies will be more aware in finding them during the routine examinations, and may be predictive of normal patterns of tooth development and/or eruption, allowing for prompt clinical intervention to avoid complicating pathology. ${ }^{5}$ Apart from third molars, impacted maxillary canines are the most common eruption disturbance in permanent dentition. There has been extensive research on this subject. Through these researches, the general tendencies of maxillary canine impaction have been repeatedly proven by many researchers. ${ }^{6}$

The prevalence of maxillary canine impaction in our study was $5.29 \%$, which is slightly higher than other studies. The prevalence of maxillary canine impaction was reported to be $1.7 \%$ in Swedish population; which was twice more common in females $(1.17 \%)$ than in males $(0.51 \%)$, and reported $2.2 \%$ in Turkish population.7 Studies reported 3\% prevalence each in Saudi and Indian populations. ${ }^{8.9}$ The incidence of canine impaction was reported $8.4 \%$ in Greek population. ${ }^{10}$

The highest reported prevalence rates of maxillary canine impaction were $12.33 \%$ in Pakistani" "and $14.45 \%$ in Australian populations. ${ }^{12}$ Ericson found the rate of impacted maxillary canines in the range of $0.9-2 \% .{ }^{13}$ Ali Gashi et al investigated the prevalence of impacted maxillary canine in a Kosovar population using the records of 8101 subjects. It was found that the prevalence of impacted maxillary canines was $1.62 \%$. It was also found that impaction of maxillary canines had ten times more occurrence than the mandibular canines. ${ }^{14}$

Females have been reported to be more frequently affected by maxillary canine impactions. ${ }^{15}$ However, the current result does not support the previous report although there is not much difference. It may be due to lesser number of sample size and requires further investigation with large samples. The present study also has a limitation that the sample population was only representative from a group of orthodontic patients.

\section{CONCLUSION}

The overall prevalence of impacted maxillary canines is found to be $5.29 \%$ among Nepalese patients requiring orthodontic treatment. The occurence of impacted maxillary canine is slightly higher in males than females. 


\section{REFERENCES}

1. Litsas G, Acar A. A review of early displaced maxillary canines. Aetiology, diagnosis and interceptive treatment. Open Dent J. 2011 5:39-47.

2. Kitan A, Kara S, Akgnulu F, Malko S. The incidence of canine transmigration and tooth impaction in a Turkish sub-population. Eur J Orthod. 2010; 32(5):575-81.

3. Ericson S, Kurol J. Radiographic assessment of canine eruption in children with clinical signs of eruption disturbances. Eur J Orthod. 1986 8:133-40.

4. Ezoddini AF, Sheikhha MH, Ahmadi H. Prevalence of dental developmental anomalies: A radiographic study. Comm Dent Health. 2007; 24:140-4.

5. Stecker SS, Beiraghi S, Hodges JS, and Peterson VS, Myers SL: Prevalence of dental anomalies in a South-East Asian population in the Minneapolis/Saint Paul metropolitan area. Northwest Dent. 2007; 86:25-8.

6. Rui H, Liang K, Kaijin H. Investigation of impacted permanent teeth except the third molar in Chinese patients through an $\mathrm{x}$-ray study. $J$ Oral Maxfac Surg. 2010; 68:762-7.

7. Shapira Y, Kuftinec MN. Early diagnosis and interception of potential maxillary canine impaction. J Am Dent Assoc. 1998; 129 (10):1450-4.

8. Zahrani AA. Impacted cuspids in a Saudi population: Prevalence, etiology and complications. Egypt Dent J. 1993; 39(1):367-74.

9. Shridaran K, Srinvasa H, Madhukar S, Sandbor S. Prevalence of impacted maxillary canines in patients attending OPD of Sri Siddharta Dental College \& Hospital of Sri Siddharta University, Tumkur, Karnataka. J Dent Sci Res. 2010; 1 (2):109-16.

10. Fardi A, Kondylidou A, Bachour Z ,Parisis N, Tsirlis A. Incidence of impacted and supernumerary teeth: Radiographic Study in a North Greek population. Med Oral Patol Oral Cir Bucal. 2011; 16(1):56-61.

11. Nazir R, Amin E, Ullahjan H. Prevalence of impacted and ectopic teeth in patients seen in a tertiary care centre, Pak Oral Dent J. 2009; 29(2):297-300.

12. Thongudomporn U, Freer TJ. Prevalence of dental anomalies in orthodontic patients. Aust Dent J. 1998; $43(6): 395-8$.

13. Ericson S, Kurol J. Resorption of maxillary lateral incisors caused by ectopic eruption of the canines. Am J Orthod Dentofacial Orthop. 1988; 94:503-13.

14. Ali G, Kamberi B, Ademi-Abdyli R. The Incidence of impacted maxillary canines in a Kosovar population. J Int Scholar Res. 2014; 130(1):1-4.

15. Cooke J, Wang HL. Canine impactions: Incidence and management. Int J Periodont Restorat Dent. 2006; 26(5):483-91. 